\title{
Reexamining the barrier effect of the Tibetan Plateau on the South Asian summer monsoon
}

\author{
G.-S. Chen, Z. Liu, and J. E. Kutzbach \\ Center for Climatic Research, University of Wisconsin-Madison, 1225 West Dayton Street, Madison, WI 53706, USA \\ Correspondence to: G.-S. Chen (gchen9@gmail.com)
}

Received: 5 August 2013 - Published in Clim. Past Discuss.: 28 August 2013

Revised: 14 May 2014 - Accepted: 19 May 2014 - Published: 30 June 2014

\begin{abstract}
The Tibetan Plateau has been conventionally treated as an elevated heat source driving the Asian monsoon system, especially for the South Asian monsoon. Numerous model simulations with general circulation models (GCMs) support this hypothesis with the finding that the Asian monsoon system is weak or absent when all elevated topography is removed. A recent model simulation shows that the South Asian summer monsoon circulation is little affected with only the Himalayas (no-Tibetan Plateau) kept as a barrier, leading to a hypothesis of the barrier "blocking" mechanism of the Tibetan Plateau. In this paper, a new series of experiments are designed to reexamine this barrier effect. We find that with the barrier, the large-scale summer monsoon circulation over South Asia is simulated in general agreement with the full Tibetan Plateau, which is consistent with the previous finding. However, there remains significant differences in both wind and precipitation fields, suggesting a role for the full Tibetan Plateau as well. Moreover, the proposed barrier blocking mechanism is not found in our experiments. The energy of the low-level air and the convection are lower and weaker over the Indian subcontinent in the full Tibetan Plateau experiment than that in the no-Tibetan Plateau experiment or the barrier only experiment, which is in contrast to the barrier blocking hypothesis. Instead, there is a similar candle-like latent heating in the middle troposphere along the southern edge of the Tibetan Plateau in both the full Tibetan Plateau and the barrier experiments, whereas this "candle heating" disappears in the no-Tibetan Plateau experiment. We propose that this candle heating is the key to understanding the mechanisms of the Tibetan Plateau on the South Asian monsoon. Future studies are needed to check the source of the "candle heating" and its effect on the Asian monsoon.
\end{abstract}

\section{Introduction}

Numerous efforts have been made to understand the mechanisms of how the Tibetan Plateau can affect the regional as well as global climate, either mechanically or thermodynamically. In 1957, Yeh et al. (1957) and Flohn (1957) first found, using observations, that the Tibetan Plateau acts as an elevated heat source for the atmosphere in summer to drive the Asian monsoon. Later, with advances in computer technologies and developments of numerical climate models, general circulation models (GCMs) were employed to study Tibetan Plateau effects on the Asian monsoon with and without the topography (Manabe and Terpstra, 1974; Hahn and Manabe, 1975; Kutzbach et al., 1989, 1993; Broccoli and Manabe, 1992; Kitoh, 1997, 2002; Tang et al., 2013) or with a gradual uplift of the Tibetan Plateau (An et al., 2001; Liu and Yin, 2002; Abe et al., 2003). These modeling results confirmed the impact of the Tibetan Plateau on the establishment and development of the Asian summer monsoon, as well as on the evolution of the Asian monsoon and the aridity in Central Asia. Yanai and $\mathrm{Wu}(2006)$ gave a thorough review of the importance of the thermal influences of the Tibetan Plateau on the Asian monsoon based on different data sets and numerical experiments. The hypothesis that the Tibetan Plateau drives the Asian monsoon by thermal forcing is hereafter referred to as the thermal mechanism. It is understood that the phrase thermal forcing includes sensible heating, latent heating (especially on the southern and eastern borders of the Tibetan Plateau) and net radiation heating as demonstrated starting with Manabe and Terpstra (1974).

However, this thermal mechanism was challenged recently by Boos and Kuang $(2010,2013)$ (hereafter BK10, BK13) because of the fact that the peaks of the upper-tropospheric temperature and the center of the Tibetan High are located 
south of the Tibetan Plateau. Alternatively, they hypothesized that the topography of the Tibetan Plateau may drive the South Asian monsoon by insulating high entropy (warm) tropical air (measured in terms of the equivalent potential temperature) over India from low entropy (cold) extratropical air at the low-levels (within $25 \mathrm{hPa}$ of the surface). Thus the warm tropical air over the Indian subcontinent is not diluted and kept favorable for moisture-driven convection (Cane, 2010). This will hereafter be referred to as the barrier blocking mechanism. With an atmospheric GCM (AGCM), BK10 showed that the model reproduced the largescale South Asian monsoon circulation by only providing the narrow orography of the Himalayas and adjacent mountain ranges.

Nonetheless, Wu et al. (2012) reported, using a different AGCM, that the Asian summer monsoon system is mainly controlled by the thermal forcing induced by the southern slope of the Tibetan Plateau, whereas the orographic mechanical blocking forcing is not essential. Thus at present there is no consensus on what mechanisms are dominant or whether the results are model dependent.

In this paper, we reexamine the barrier effect of the Tibetan Plateau with the same GCM model and resolution as the model used in BK10. However, there are some important differences in our experimental design. First, considering that the orography in other regions may contribute to the changes of the Asian monsoons, such as the high land over Africa and the Middle East, we only remove the mountains over the Tibetan Plateau region, and leave orography elsewhere unchanged to show the Tibetan Plateau effect on the Asian monsoons. In contrast, mountains were removed globally with surface elevations set to zero in the no-mountain experiment of BK10. Second, when we remove the Tibetan Plateau, only the portion of the plateau higher than $1200 \mathrm{~m}$ is removed by setting the topography to $1200 \mathrm{~m}$ at each model grid in the Tibetan Plateau region. The reason for retaining a plateau elevation of $1200 \mathrm{~m}$ is to avoid creating a "valley" in the region of the high plateau because areas around the plateau are as high as $1200 \mathrm{~m}$. Also, retaining this minimum elevation avoids altering the river directions in the CLM component. Third, we use the fully coupled atmosphereocean-land model. BK10 only used the atmospheric component of the model with prescribed sea surface temperature (SST). Therefore their study did not account for the ocean circulation changes due to the orography change. Early studies show that experiments with a slab ocean (Kutzbach et al., 1993; Kitoh, 1997) or a coupled ocean (Kitoh, 2002; Abe et al., 2003) could have significantly different sea surface temperatures (SSTs).

The structure of the paper is the following. Section 2 describes the model and experimental design. The responses of the Asian monsoon to different topographic settings are shown in Sect. 3 and the mechanisms of the responses are studied in Sect. 4. The conclusion and discussion are provided in Sect. 5 .

\section{Model and experiment design}

\subsection{Model}

The model used in this study is the Community Earth System Model, Version 1.0 (CESM1.0) of the National Center for Atmospheric Research (NCAR), which is a state-ofthe-art fully coupled global climate model. The fully coupled model includes the Community Atmosphere Model (CAM4/CAM5), Community Land Model (CLM4), Parallel Ocean Program (POP2), Community Ice Sheet Model (CISM), and Community Ice code (CICE4). To have the same configurations of the model as those used in BK10, CAM4 is chosen for the Community Atmosphere Model. The finite volume dynamical core is chosen for CAM4. The horizontal resolution used is $1.9^{\circ}$ (latitude) $\times 2.5^{\circ}$ (longitude) for CAM4 with 26 vertical levels and CLM4 has identical horizontal resolution.

The CESM1.0 chosen here is identical to the Community Climate System Model version 4 (CCSM4). CESM1.0 has numerous improvements compared with it predecessors (Gent et al., 2011). Both shallow convection and deep convection are included. The changes to the deep convection scheme improve the El Niño-Southern Oscillation (ENSO) and Madden-Julian Oscillation. The new parameterizations in POP2 lead to an improved simulation of the Gulf Stream path and the North Atlantic Ocean meridional overturning circulation. Changes to the CLM4 improve the annual cycle of water storage in the tropics. The simulations of the Asian and Australian monsoons are also improved (Meehl et al., 2012). The maximum values of precipitation in the eastern Arabian Sea and Bay of Bengal are closer to observations. Also the location and magnitude of orographic precipitation over the southern edge of the Tibetan Plateau and over the Western Ghats are generally improved, although precipitation is still higher than observed in these regions (Fig. 2a). With the present-day topography, the model produces similar positions for the centers of the upper-troposphere temperature and low-level entropy as observed, though the peak values of the temperature and the entropy are lower than the observed (Boos and Kuang, 2010).

\subsection{Experiments}

Three experiments were performed (Fig. 1). The first experiment was designed with the present-day topography of the Tibetan Plateau, termed as FULL_TP (Fig. 1). In the noTibetan Plateau experiment, we only removed the portion of the plateau higher than $1200 \mathrm{~m}$ by setting the topography to $1200 \mathrm{~m}$ at each model grid in the Tibetan Plateau region (60$115^{\circ} \mathrm{E}, 22-54^{\circ} \mathrm{N}$ ) (Fig. 1). We refer to this experiment as NO_TP (Fig. 1). In the third experiment, a barrier was retained along the southern edge of the Tibetan Plateau with the maximum height of two-thirds of the maximum height of the Tibetan Plateau at a particular longitude between $60^{\circ}$ 

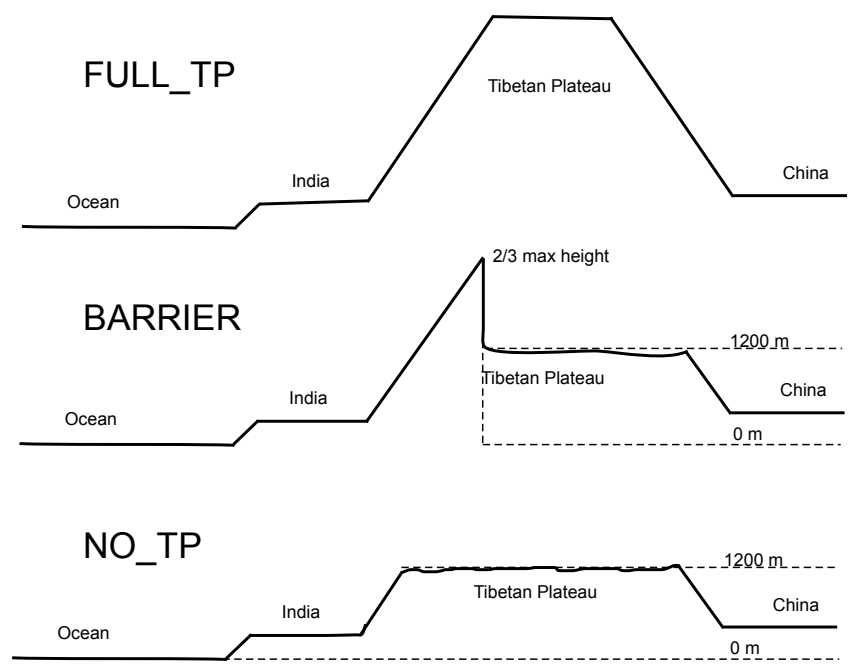

Figure 1. Schematic topographies used for the FULL_TP, BARRIER, and NO_TP experiments, respectively. The dashed lines of the elevation of $0 \mathrm{~m}$ denote the topographies used in BK10's experiments.

and $115^{\circ} \mathrm{E}$ to mimic the Himalayas (Fig. 1). We followed the approach of BK10 exactly to create a barrier, but north of the barrier, elevations were not set to zero. Instead, they were identical to NO_TP. This third experiment is termed as BARRIER.

Therefore, the difference between the climate of the FULL_TP and NO_TP (BARRIER and NO_TP) should give the effect of the full Tibetan Plateau (barrier) on the Asian monsoon. Each experiment was run for 60 years. The last 50 years of each experiment are analyzed in this study. Except for the topography, all other boundary conditions in all experiments were kept at the present-day conditions. Student's $t$ tests are used to identify the statistical significance of the differences between the simulations. All differences described in the text are statistically significant at the $95 \%$ significance level.

\section{Results}

\subsection{Full Tibetan Plateau effect}

With the full Tibetan Plateau (FULL_TP minus NO_TP) present, the model produces a stronger Asian summer monsoon circulation, with significant increase in the wind speed (up to $3 \mathrm{~m} \mathrm{~s}^{-1}$ ) over the region of the Somali Jet, the Indian continent, and the East Asia region (Fig. 2b). Climatologically, in the upper troposphere, there is a huge anticyclone known as the South Asian High with its center over the southern periphery of the plateau, westerly winds to the north, and easterly winds to the south (Fig. 3a). With a higher Tibetan Plateau, an anticyclone anomaly is generated over the western Tibetan Plateau region, which indicates that the
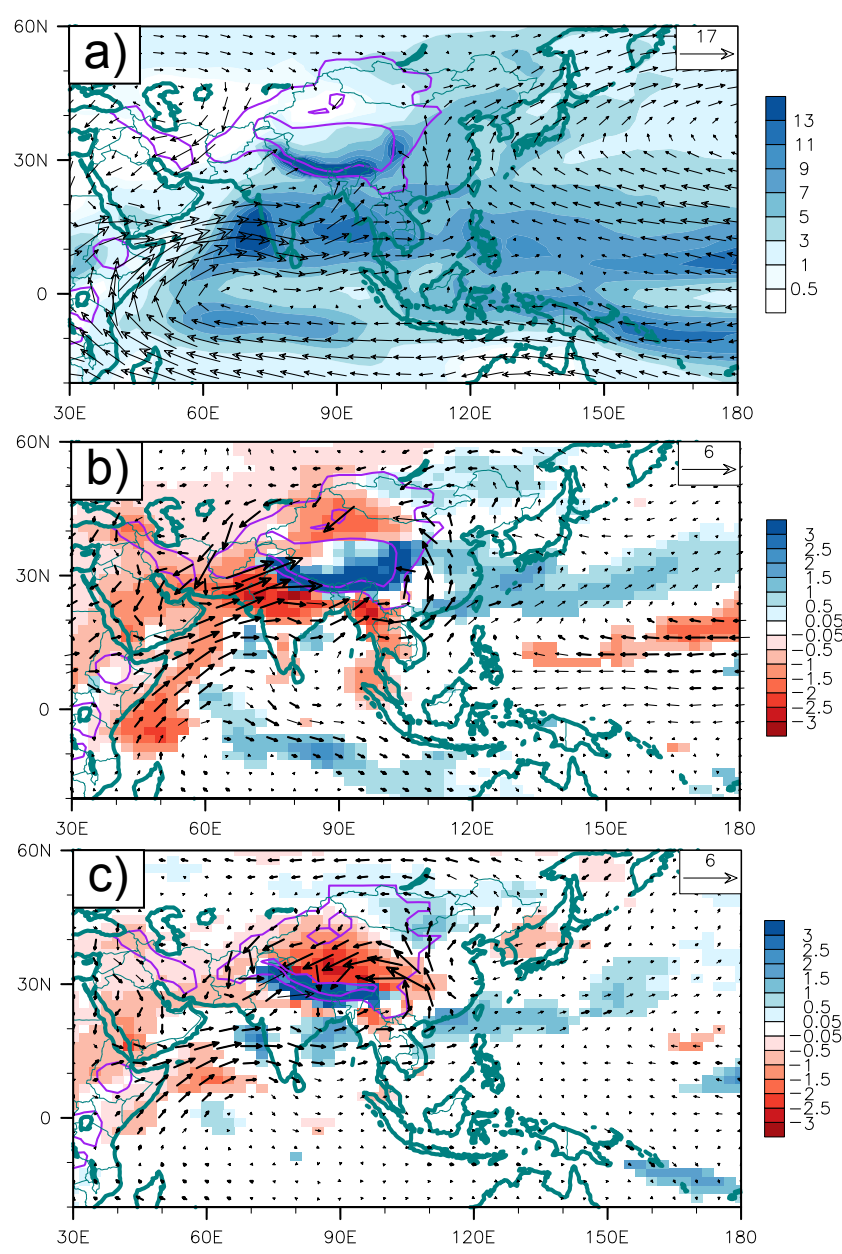

Figure 2. JJA climatology of surface wind $\left(\mathrm{m} \mathrm{s}^{-1}\right)$ and precipitation $\left(\mathrm{mm} \mathrm{day}^{-1}\right)$ for FULL_TP (a) and JJA differences in surface wind $\left(\mathrm{m} \mathrm{s}^{-1}\right)$ and precipitation $\left(\mathrm{mm} \mathrm{day}^{-1}\right)$ for FULL_TP minus NO_TP (b) and BARRIER minus NO_TP (c). Blue indicates positive values, red indicates negative values of precipitation change. Only significant values are shown for precipitation (color shading). Bold vectors indicates the significant changes in wind. Purple contour lines denote the elevations of 1200 and $3000 \mathrm{~m}$.

South Asian High significantly increases (Fig. 3b). Precipitation strongly increases over the East Asian monsoon region by $1 \mathrm{~mm} /$ day and the southern/eastern edge of the Tibetan Plateau by $3 \mathrm{~mm}$ day $^{-1}$ (blue color) (Fig. 2b). These changes are similar to those found in other model simulations (Hahn and Manabe, 1975; Kutzbach et al., 1989, 1993; Kitoh, 1997, 2002; Liu and Yin, 2002; Abe et al., 2003; Boos and Kuang, 2010).

However, precipitation over the region of the Somali Jet, the north of India, and Southeastern Asia decrease significantly (red color). This result is significantly different from the findings in the previous model studies with fixed or slab ocean where all global mountains were removed (Hahn and Manabe, 1975; Kutzbach et al., 1989, 1993; Kitoh, 1997, 2002; Liu and Yin, 2002). A similar finding can be found in 

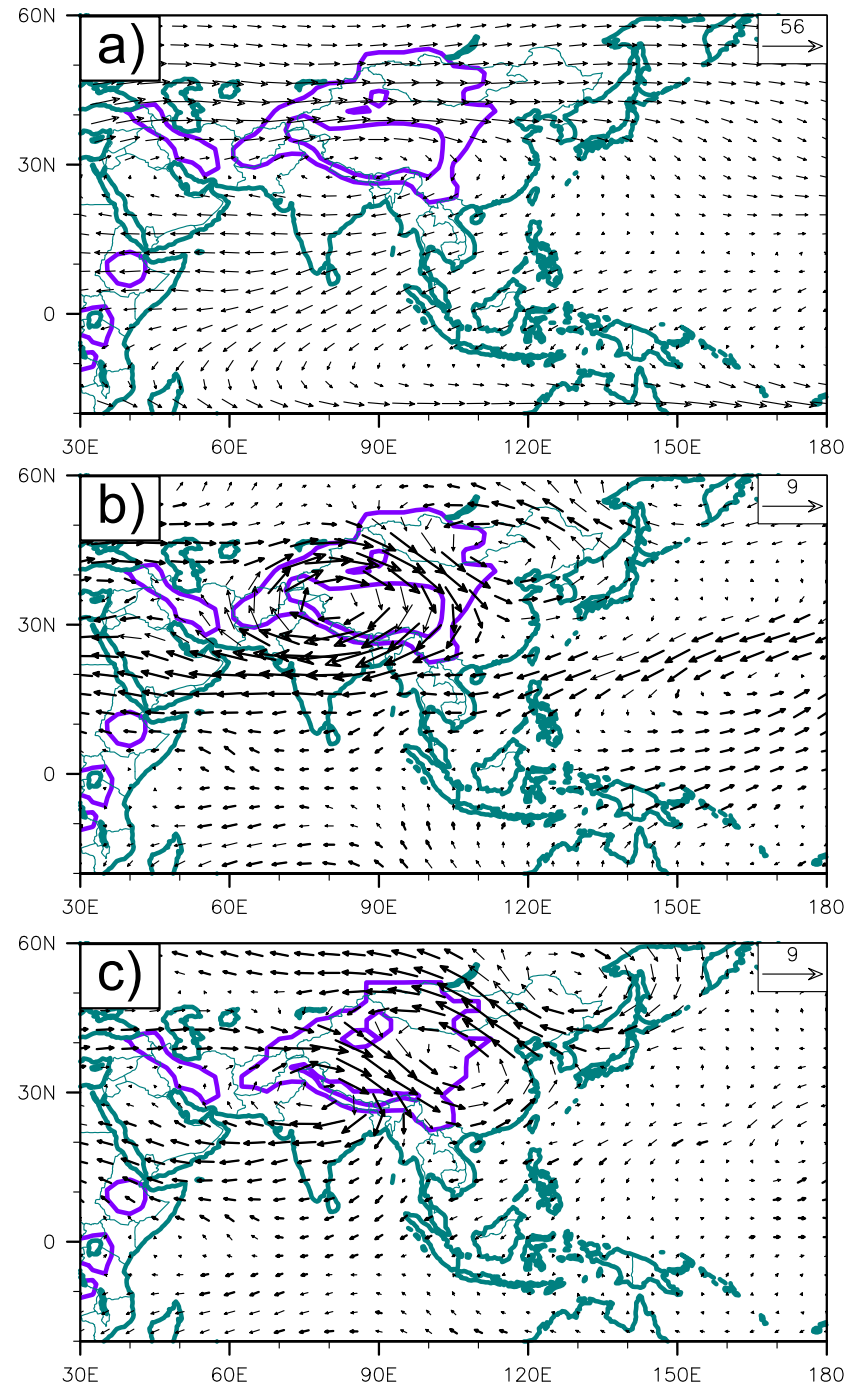

Figure 3. JJA climatology of wind field at $200 \mathrm{hPa}\left(\mathrm{m} \mathrm{s}^{-1}\right)$ for Full_TP (a), differences in wind field at $200 \mathrm{hPa}\left(\mathrm{m} \mathrm{s}^{-1}\right)$ for FULL_TP minus NO_TP (b), and differences in wind field at $200 \mathrm{hPa}\left(\mathrm{m} \mathrm{s}^{-1}\right)$ for BARRIER minus NO_TP (c). Bold vectors indicate the significant changes in wind at $P<0.05$. Purple contour lines denote the elevations of 1200 and $3000 \mathrm{~m}$.

Abe et al. (2003) in which a fully coupled model was used, but the decreases in precipitation are limited to the north of the Arabian Sea and Southeastern Asia. We note that our modeling result of precipitation decrease (over northern India due to the Tibetan Plateau) is supported by paleoclimate data. A wealth of geologic observations indicates that when the eastern part of the Tibetan Plateau expanded and uplifted over the past 15-10 Ma, precipitation increased over the eastern Tibetan Plateau, while northwestern India became drier (Molnar and Rajagopalan, 2012). The cause of the decreases in precipitation over northern India was studied in detail in Molnar and Rajagopalan (2012). Due to the heating of the Tibetan Plateau, especially of the eastern Tibet Plateau, sub-
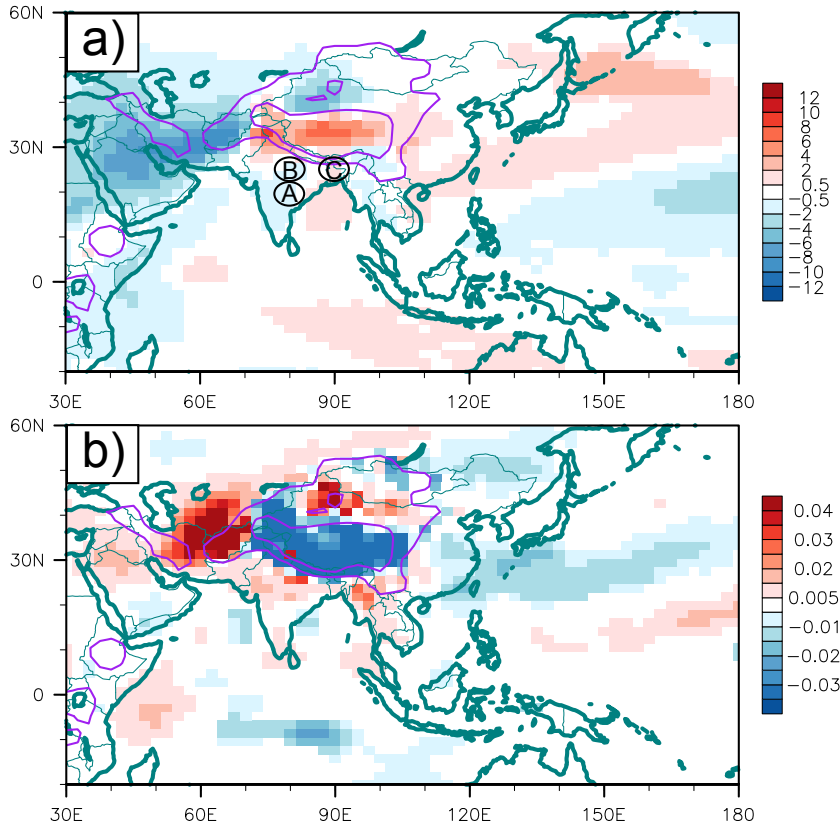

Figure 4. JJA differences in low-level entropy (Equivalent potential temperature on a terrain-following model level about $20 \mathrm{hPa}$ above the surface) (K) (a) and vertical velocity at $500 \mathrm{hPa}\left(\mathrm{Pa} \mathrm{s}^{-1}\right)$ (b) for FULL_TP minus NO_TP. Red indicates positive anomaly. Blue indicates negative anomaly. Only significant values are shown. Letters of A, B, and C indicate the locations of the three points used in Table 1, respectively. Purple contour lines denote the elevations of 1200 and $3000 \mathrm{~m}$.

sidence was generated to the west via the monsoon-desert mechanism, as proposed by Rodwell and Hoskins (1996), due to the western propagation of a Rossby wave (Fig. 4b). Thus the subsidence suppresses precipitation. We also note that the subsidence over the broad areas adjacent to the Tibetan Plateau is due to the divergence caused by the local convergence over the Tibetan Plateau (Fig. 4b). It is worth pointing out that by using a coupled dynamic ocean rather than slab ocean, precipitation is reduced over the region of the Somali Jet due to the decrease in SSTs caused by strong wind-driven upwelling (figure not shown). This also contributes to less precipitation over northwestern India due to less available transported moisture.

\subsection{Barrier effect}

With a barrier along the southern edge of the Tibetan Plateau (BARRIER minus NO_TP), the large-scale South Asian monsoon circulation is also strengthened (Fig. 2c, bold vectors). Surface wind increases over the southern Arabian Sea, the south of India, the Bay of Bengal, Southeastern Asia, and East Asia - especially the part of East Asia north of the "barrier". The South Asian monsoon circulation is therefore simulated in general agreement with the full Tibetan Plateau effect, although with some differences (Fig. 2b). However, 
Table 1. Convective available potential energy (CAPE) for point $\mathrm{A}$ $\left(80^{\circ} \mathrm{E}, 20^{\circ} \mathrm{N}\right)$, point $\mathrm{B}\left(80^{\circ} \mathrm{E}, 25^{\circ} \mathrm{N}\right)$, and point $\mathrm{C}\left(90^{\circ} \mathrm{E}, 25^{\circ} \mathrm{N}\right)$ over the northern Indian continent in the FULL_TP and NO_TP experiments. The locations of the three points are shown in Fig. 3.

\begin{tabular}{llll}
\hline & Point A & Point B & Point C \\
\hline full_TP & $1818 \mathrm{~J} \mathrm{Kg}^{-1}$ & $1869 \mathrm{~J} \mathrm{Kg}^{-1}$ & $2792 \mathrm{~J} \mathrm{Kg}^{-1}$ \\
no_TP & $1960 \mathrm{~J} \mathrm{Kg}^{-1}$ & $2402 \mathrm{~J} \mathrm{Kg}^{-1}$ & $3048 \mathrm{~J} \mathrm{Kg}^{-1}$
\end{tabular}

the overall precipitation field and the wind field in other regions have significant differences relative to the full Tibetan Plateau experiment. For example, with the full Tibetan Plateau, there is much more precipitation in East Asia and the eastern region of the plateau (more blue color in East Asia and the eastern region of the plateau in Fig. 2b) and much less precipitation in northern India (more red color in the northern India in Fig. 2b). Also the southerly monsoon flow over East Asia and the southwesterly monsoon flow over northern India are stronger in the full Tibetan Plateau experiment. It is also noteworthy that surface wind anomaly over northwestern India is significantly decreased with the barrier only, showing a southward shift of the wind anomaly compared with Fig. $2 b$. These significant differences in precipitation and wind field indicate that although the large-scale South Asian monsoon circulation are simulated in both the BARRIER experiment and the FULL_TP experiment, the presence of the northern portion of the Tibetan Plateau has very important effects on the East Asian monsoon and the northern Indian monsoon.

With the barrier along the southern edge of the Tibetan Plateau, an anticyclone anomaly is also generated over the west of the barrier in the upper troposphere (Fig. 3c). However, this anticyclone anomaly generated by barrier only is weaker than the anticyclone anomaly generated by the Tibetan Plateau in Fig. 3b. Also the center of the anticyclone shifts to the south. Thus the easterly wind anomaly over northwestern India is significantly decreased. The southward shift of the anticyclone anomaly and the decrease in the easterly wind anomaly over northwestern India well explain the significant decrease in surface wind anomaly over northwestern India in Fig. 2c.

\section{Mechanism of the full Tibetan Plateau}

In this section, we examine the barrier blocking mechanism. If the full Tibetan Plateau produces a strong South Asian summer monsoon (circulation) mainly by the barrier blocking mechanism proposed by BK10, then the low-level entropy should be higher over the Indian subcontinent in the FULL_TP experiment than in the NO_TP experiment. Convection should also be stronger in the FULL_TP experiment. Figure 4 shows the difference in low-level entropy and vertical velocity at $500 \mathrm{hPa}$ between the FULL_TP and NO_TP experiments (FULL_TP minus NO_TP). We find, however,
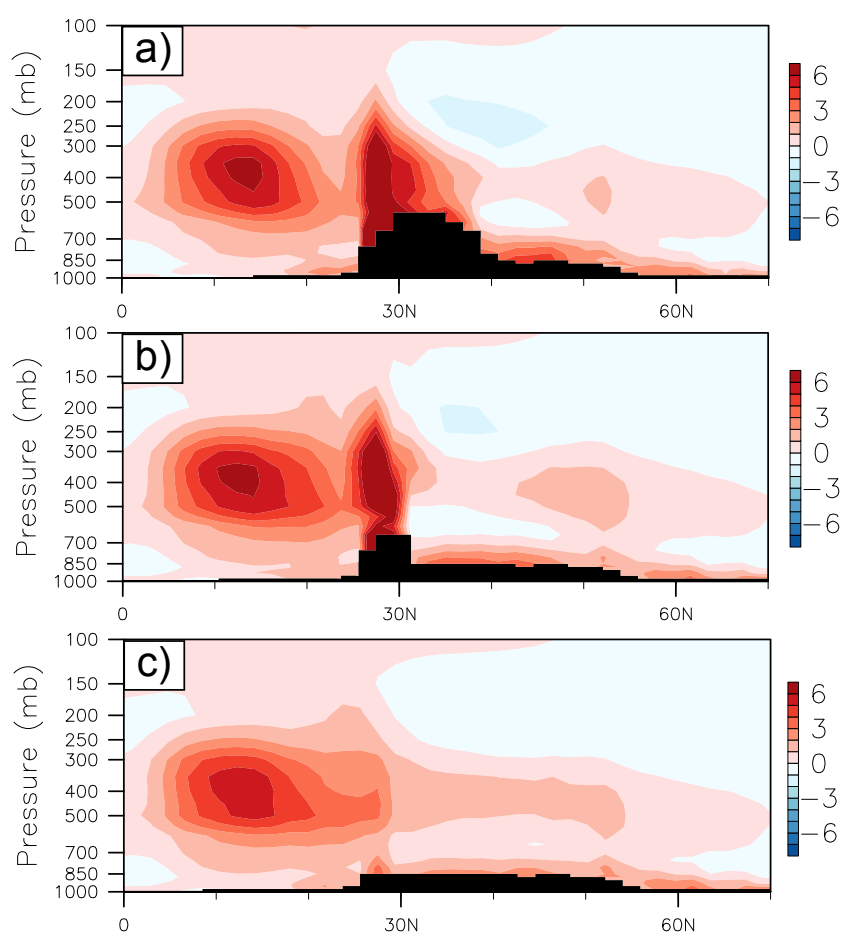

Figure 5. Meridional cross section of total diabatic heating $\left(\mathrm{K} \mathrm{day}^{-1}\right)$ averaged between 85 and $95^{\circ} \mathrm{E}$ for FULL_TP (a), BARRIER (b), and NO_TP (c) experiments, respectively. For all the panels, black shaded region denotes the topography in the experiment.

that the low-level entropy in the FULL_TP experiment is significantly lower than that in the NO_TP experiment over the Indian subcontinent (Fig. 4a, blue color), although the lowlevel entropy is higher over the western and middle Tibetan Plateau in FULL_TP experiment. The convective available potential energy (CAPE) in the full TP experiment is lower at the selected three points in the Indian subcontinent, respectively (Table 1), and the anomaly of vertical velocity at $500 \mathrm{hPa}$ is positive (Fig. 4b), which indicates the convection is weaker in the FULL_TP experiment over the Indian subcontinent. This is the opposite of what we would expect based on the barrier blocking mechanism, suggesting that the proposed hypothesis of the barrier blocking mechanism can not explain or at least can not fully explain the changes in the Asian summer monsoon shown in Fig. 2b. Note that in Fig. $2 b$ the "barrier" of the higher regions of the plateau is further north than the Himalayas barrier, but the basic conclusion is that the barrier in Fig. $2 \mathrm{~b}$ does not produce the hypothesized effects as proposed in BK10.

What mechanism causes the changes in the Asian summer monsoon in Fig. 2b? Why does the BARRIER also produce a strong South Asian monsoon circulation in Fig. 2c? While our study raises questions about the proposed barrier blocking mechanism, it remains possible that the diabatic heating forcing of the full Tibetan Plateau is similar to that of the barrier and might help explain the somewhat similar results of 
the two kinds of orographic forcing. Figure 5 shows the vertical profile of total diabatic heating along $90^{\circ} \mathrm{E}$ in the three experiments. One can see that both the full Tibetan Plateau and the barrier produce a similar candle-like diabatic heating along the southern edge of the Tibetan Plateau between $26^{\circ}$ and $30^{\circ} \mathrm{N}$ (Fig. 5a, b). But this "candle heating" vanishes in the NO_TP experiment (Fig. 5c). Our analyses show that this candle heating is mainly contributed by the latent heating due to the convection along the southern edge of the Tibetan Plateau or the barrier (figures not shown). However, the mechanism of the convection could not be studied with the experiments we have now. More experiments are needed to explore the source of the candle heating.

\section{Conclusion and discussion}

In this paper, we reexamine the effect of the Tibetan Plateau on the Asian monsoon with a fully coupled GCM and also the effect of the barrier blocking mechanism proposed by BK10. Our results show that the barrier produces a strong South Asian monsoon circulation over southern India, which generally agrees with the previous finding of BK10. However, there are significant differences in both the wind field and precipitation field between the barrier simulation and the full Tibetan Plateau simulation. With the full Tibetan Plateau, there is much more precipitation over the East Asian monsoon region and less precipitation over northern India. Also, the southerly monsoon flow over East Asia and the southwesterly monsoon flow over northern India are stronger in the FULL_TP experiment than in the BARRIER experiment. These significant differences in precipitation and wind field indicate that the northern portion of the Tibetan Plateau has important effects on the East Asian monsoon and the northern Indian monsoon. The result of less precipitation over northern India in the full Tibetan experiment differs significantly from the findings in the previous model studies with fixed or slab ocean, where all global mountains were removed, and is supported by a wealth of geologic observations (Molnar and Rajagopalan, 2012).

Whereas BK10 proposed that the full Tibetan Plateau can be treated as a "wide" barrier that drives the South Asian monsoon by blocking the extra-tropical cold air that would dilute the convective potential of the tropical warm air, our experiments do not strongly support this mechanism. By checking the low-level entropy changes in our experiments, we find the proposed barrier blocking mechanism can not explain the climatic response to the full Tibetan Plateau because the low-level entropy (convection) is lower in the full Tibetan Plateau experiment over the Indian subcontinent than that in the no-Tibetan Plateau experiment or the barrier only experiment. This change is the opposite of the hypothesis. As mentioned, the location of the barrier, by treating the full Tibetan Plateau as a "wide" barrier, is farther north than the location of the barrier in the BARRIER experiment. However, our ex- periments with changing the location of a barrier show that the change in the location of a barrier does not significantly affect the low-level entropy over the Indian subcontinent.

Instead, our analyses indicate that the very strong and deep diabatic heating ("candle heating") in the middle troposphere along the southern edge of the Tibetan Plateau in both the full Tibetan Plateau and the barrier experiments may be a key to increased understanding of the driving mechanisms of the Tibetan Plateau on the Asian monsoon. We also note that the heating north of the "candle" over the Tibetan Plateau in the full Tibetan Plateau experiment (Fig. 4a) could help explain the increases in precipitation over East Asia and decreases in northern India.

This candle heating is mainly latent heating released by the deep convection along the southern slope of the Tibetan Plateau. The convection may be generated (or enhanced) by the SHAP mechanism (Wu et al., 2007, 2012). Our results may therefore support and complement the hypothesis of $\mathrm{Wu}$ et al. (2012) that the sensible heating on the slope is the driver of the Asian monsoon. There is no doubt that there is a barrier effect of the Tibetan Plateau on the Asian monsoon. However, the question is: what is the mechanism of the barrier effect? Our current experiments only show that the barrier blocking mechanism based on the low-level entropy change proposed by BK10 can not explain the results shown here. It is still possible that a barrier heating mechanism or a new barrier blocking mechanism, or the combination of the two could explain the effect of the Tibetan Plateau on the Asian monsoon. We are currently working on developing new experiments to explore the barrier effect. Our future work will be reported in another paper.

Acknowledgements. We acknowledge the support of National Science Foundation (NSF) grants 0908117,1212024 to the University of Wisconsin-Madison, National Nature Science Foundation of China (NSFC) grant no. 40921120406 to our Chinese colleagues, and climate model and computer resources of the National Center for Atmospheric Research (NCAR). We give thanks to William R. Boos for the code of calculating low-level entropy.

Edited by: R. Saraswat

\section{References}

Abe, M., Kitoh, A., and Yasunari, T.: An evolution of the Asian summer monsoon associated with mountain uplift - Simulation with the MRI atmosphere-ocean coupled GCM, J. Meteorol. Soc. Jpn., 81, 909-933, 2003.

An, Z., Kutzbach, J. E., Prell, W. L., and Porter, S. C.: Evolution of Asian monsoons and phased uplift of the Himalayan Tibetan plateau since Late Miocene times, Nature, 411, 62-66, 2001.

Boos, W. R. and Kuang, Z. M.: Dominant control of the South Asian monsoon by orographic insulation versus plateau heating, Nature, 463, 218-222, doi:10.1038/Nature08707, 2010. 
Boos, W. R. and Kuang, Z. M.: Sensitivity of the South Asian monsoon to elevated and non-elevated heating, Sci. Rep.-Uk, 3, 1192, doi:10.1038/Srep01192, 2013.

Broccoli, A. J. and Manabe, S.: The Effects of Orography on Midlatitude Northern-Hemisphere Dry Climates, J. Climate, 5, 1181-1201, 1992.

Cane, M. A.: A Moist Model Monsoon, Nature, 463, 163-164, 2010.

Flohn, H.: Large-scale aspects of the "summer monsoon" in south and east Asia, J. Meteor. Soc. Japn., 75, 180-186, 1957.

Gent, P. R., Danabasoglu, G., Donner, L. J., Holland, M. M., Hunke, E. C., Jayne, S. R., Lawrence, D. M., Neale, R. B., Rasch, P. J., Vertenstein, M., Worley, P. H., Yang, Z. L., and Zhang, M. H.: The Community Climate System Model Version 4, J. Climate, 24, 4973-4991, 2011.

Hahn, D. G. and Manabe, S.: The role of mountains in the south Asian monsoon circulation, J. Atmos. Sci., 32, 1515-1541, 1975.

Kitoh, A.: Mountain uplift and surface temperature changes, Geophys. Res. Lett., 24, 185-188, 1997.

Kitoh, A.: Effects of large-scale mountains on surface climate A coupled ocean-atmosphere general circulation model study, J. Meteorol. Soc. Jpn., 80, 1165-1181, 2002.

Kutzbach, J. E., Guetter, P. J., Ruddiman, W. F., and Prell, W. L.: Sensitivity of Climate to Late Cenozoic Uplift in Southern Asia and the American West - Numerical Experiments, J. Geophys. Res.-Atmos., 94, 18393-18407, 1989.

Kutzbach, J. E., Prell, W. L., and Ruddiman, W. F.: Sensitivity of Eurasian Climate to Surface Uplift of the Tibetan Plateau, J. Geol., 101, 177-190, 1993.

Liu, X. D. and Yin, Z. Y.: Sensitivity of East Asian monsoon climate to the uplift of the Tibetan Plateau, Palaeogeogr. Palaeocl., 183, 223-245, 2002.
Manabe, S. and Terpstra, T. B.: The Effects of Mountains on the General Circulation of the Atmosphere as Identified by Numerical Experiments, J. Atmos. Sci., 31, 3-42, 1974.

Meehl, G. A., Arblaster, J. M., Caron, J. M., Annamalai, H., Jochum, M., Chakraborty, A., and Murtugudde, R.: Monsoon Regimes and Processes in CCSM4. Part I: The Asian-Australian Monsoon, J. Climate, 25, 2583-2608, 2012.

Molnar, P. and Rajagopalan, B.: Late Miocene upward and outward growth of eastern Tibet and decreasing monsoon rainfall over the northwestern Indian subcontinent since similar to $10 \mathrm{Ma}$, Geophys. Res. Lett., 39, L09720, doi:10.1029/2012GL051305, 2012.

Rodwell, M. J. and Hoskins, B. J.: Monsoons and the dynamics of deserts, Q. J. Roy Meteor. Soc., 122, 1385-1404, 1996.

Tang, H., Micheels, A., Eronen, J. T., Ahrens, B., and Fortelius, M.: Asynchronous responses of East Asian and Indian summer monsoons to mountain uplift shown by regional climate modelling experiments, Clim. Dynam., 40, 1531-1549, 2013.

Wu, G. X., Liu, Y. M., Wang, T. M., Wan, R. J., Liu, X., Li, W. P., Wang, Z. Z., Zhang, Q., Duan, A. M., and Liang, X. Y.: The influence of mechanical and thermal forcing by the Tibetan Plateau on Asian climate, J. Hydrometeorol., 8, 770-789, 2007.

Wu, G. X., Liu, Y. M., He, B., Bao, Q., Duan, A. M., and Jin, F. F.: Thermal Controls on the Asian Summer Monsoon, Sci. Rep.-Uk, 2, 404, doi:10.1038/srep00404, 2012.

Yanai, M. and Wu, G.-X.: Effects of the tibetan plateau, in: The Asian Monsoon, edited by: Wang, B., Springer, 513-549, 2006.

Yeh, T., Lo, S., and Chu, P.: The wind structure and heat balance in the lower troposphere over Tibetan Plateau and its surrounding, Acta Meteorol. Sin., 28, 108-121, 1957. 